\title{
REFLECTION
}

\section{Professional Loneliness and the Loss of the Doctors' Dining Room}

\author{
Jobn J. Frey III, MD \\ Family Medicine and Community Health, \\ University of Wisconsin School of \\ Medicine
}

Conflicts of interest: author reports none.

\section{CORRESPONDING AUTHOR}

John J. Frey III, MD

Emeritus Professor of Family Medicine and Community Health

University of Wisconsin School of Medi-

cine and Public Health

8 Avenida de La Scala

Santa Fe, New Mexico 87506

john.frey@fammed.wisc.edu

\begin{abstract}
Historically, family physicians moved among all the venues of medical careoffice, hospital, community-and were a part of a connected professional community. That connected community was sustained in great part through informal gatherings of clinicians in hospitals, clinics, and professional organizations. The current fragmentation of medicine into narrowly defined, boundaried workspaces and job descriptions, as well as the increasing size of practices has negatively affected the professional culture in which physicians work. These structural changes have led to an increasing sense of professional loneliness that not only threatens the quality of clinical care by replacing personal discussions about patients but also poses risks to physician personal and professional wellbeing.
\end{abstract}

Ann Fam Med 2018;16:461-463. https://doi.org/10.1370/afm.2284

$\mathrm{n}$ all of the current handwringing about physician burnout and dysphoria, the loss of professional connections and relationships among physicians-being a part of a professional community-is rarely mentioned as a source of professional unhappiness. Being a physician in today's world begins to feel lonely and isolated, particularly in larger systems which increasingly dominate medicine. While relationships with patients over time are acknowledged as the source of satisfaction that keeps physicians vital, dedicated, and learning, ${ }_{1}^{1}$ there are fewer discussions about the changing relationships with colleagues.

Almost 50 years ago, during my internship at one of the largest county hospitals in the country, each of us had a tiny room in a dormitory full of interns and residents from every country imaginable. On the second floor was the United Nations of hospital cafeterias. At $11 \mathrm{pm}$, the cafeteria was opened, offering leftovers for physicians on call. Probably 60 house staff and almost equal numbers of medical students showed up every night to talk about admissions and stories from the day and drink coffee. We were exhausted, but life was vivid and memorable and collegial. As a medical student, I sat and ate and listened and imagined what was coming next.

When I started practice at a community health center in a new family medicine residency program, the 4 faculty members at the clinic would have lunch most Wednesdays at the corner booth at a local Chinese restaurant. We would talk about the practice but we also talked about many other things-resident behavior, our family struggles, local colleges, books, neighborhood events. We talked, as Lewis Carrol put it, "... of many things: Of shoes_-and ships_-and sealing-wax-Of cabbages-and kings-And why the sea is boiling hot-And whether pigs have wings."2 But we rarely talked about clinic business.

\section{THE DINING ROOM}

At the city hospital where my family medicine residency was based, a room off the main cafeteria was labeled "the doctor's dining room" 
where physicians would gather their trays for lunch or breakfast or coffee breaks. We were among the only "new" family doctors in town for a generation and talking in the dining room was our introduction to the culture-both medical and community-of the place. We new doctors could ask consultants questions about management of a patient and they could tell us their thoughts about the case. We got to know each other, respect our differences, ask questions, and hear a number of points of view about managing a case. I remember asking one of the senior surgeons in the town about having a man with a peptic ulcer see him for possible surgery. The surgeon was intimidating, deferred to by staff and colleagues and called "Doctor" by everyone. But he was kind to me, saying he would be happy to see the patient while reminding me that sometimes the results from surgery were worse than the problem. It didn't hurt that he remembered my patients' names and something about their lives when he talked with me. I got one letter back from him that said "John: Mr. X is an interesting guy with good stories. His gallbladder is out, things went well, and he is on his way back to you." This previously intimidating doctor became my main surgical consultant from that point on.

In those first years, the doctors' dining room and our Chinese lunches were my source of continuing political and medical acculturation. They were safe places to raise questions, set plans, and learn what was important about the hospital organization, the nature of hospital management, and the long history of the place. But we younger physicians and residents, in a fit of egalitarian arrogance that saw any hierarchy in medicine as something to be overcome, successfully petitioned to "open up" the doctor's dining room to everyone. After that change, in the big cafeteria where everyone mingled, the safety dissipated, the conversations ceased and we began sitting alone. Looking back nowwith regret, like Joni Mitchell sang in "Big Yellow Taxi"

"Don't it always seem to go

That you don't know what you've got

Till it's gone"3

Today, lunches are solitary, eaten at desks from plastic containers from home or takeout from local restaurants while catching up on email, writing charts before the afternoon begins, or answering online patient inquiries. Even in common spaces and nurses' stations, everyone sits silently in front of a computer screen. No talking of Cabbages and Kings or pigs with wings these days. Meetings are functional, organizational, and informational. People come late and leave early. "Send me an email" we say.

\section{THE DISCONNECTED WORKPLACE}

Generalists of all types are less engaged in hospital care and, as a result, have much less personal contact with the consultants they use. The times spent with colleagues in labor and delivery, in the ED, or morning rounds are being replaced by e-consults and wordy electronic progress notes more filled with facts than information. Primary care clinicians don't get personal notes or phone calls back-they are told that notes in the EHR should suffice. Phone calls waste time. Access metrics-getting the patient to a consultant quickly_seem more important to large organizations than relationships. A colleague told the story of her early days in practice when one of her patients was admitted to pediatrics with failure to thrive and as she walked in the teaching room, the Chair of Pediatrics said to the assembled residents "now we have a chance to hear about this child's life and history-his family doctor is here." I have many colleagues who have never personally met the hospitalists who are members of the same large medical group. In fact, they may not have met the family doctors in their group from a different clinic.

Doctors' dining rooms and casual lunches are considered by health systems, and sadly often by physicians, as being non-productive-time that does not generate revenue and gets in the way of getting EHR chores finished. The problem is that increasing numbers of isolated doctors are a risk to themselves, their patients and the profession. Not creating time and space for connecting professionally may be an additional burden for women physicians for whom the stresses of work-life balance are already well known.

Although learning to talk with patients is a part of every medical school curriculum, learning to talk with each other has not been. Professional isolation used to be considered an affliction of solo rural physicians. But large buildings in large health systems in big cities are among the loneliest and most alienated places to practice these days. Small town doctors, it turns out, are generally more engaged with colleagues, staff, and community. In small clinics, everyone knows each other. Big clinics offer anonymity. Beyond a certain number of people in a clinic, familiarity disappears. "Practice teams" are often attempts to break large practices into meaningful working relationships but even team meetings become less spontaneous, are scheduled with agendas, and rarely include "how are we all doing?" We barely know who each other are. Some of the interest in direct primary care practice may be driven by a desire for a practice environment where doctors know something about everyone in the office.

Remedying professional loneliness begins in training. A Canadian study found that increasing social 
interactions and friendships among medical students decreases the tendency to experience emotional and physical exhaustion. ${ }^{4}$ Another Canadian study found that the more related physicians felt to each other, the higher the level of professional well-being, professional satisfaction, and energy in their work. ${ }^{5}$ Connectedness is one antidote to exhaustion. It is much easier to see pain in a colleague's face than to search for it in their text messages. Communication is physical and nonverbal. The disappearance of spending time with each other as colleagues in a community of professionals has diminished the chances of being helpful and empathetic when it is needed. ${ }^{6}$

\section{THE COST OF PROFESSIONAL LONELINESS}

Physicians are notorious for delaying requests for help. We engage in hard and often emotionally draining work which certainly has its rewards but frequently leaves us wondering if we have made the difference we had hoped to in our patients' lives. Our professional struggles are often with ourselves as much as with our patients. Professional isolation and loneliness only make it worse. Struggling alone is a reality at times for everyone. However, expecting a colleague to send an email saying "help" assumes they know when and how to ask. More often than not, the "help" is in a colleague's demeanor, voice, eyes, giving us a chance to put a hand on a shoulder and ask, "Are you all right?" Having solitary lunches or eating a yogurt at one's desk doesn't really improve our social intelligence.

The three questions that make up the short form of the UCLA loneliness scale which has been in use for decades are: "How often do you feel like you lack companionship?" "How often do you feel left out?" and, "How often do you feel isolated from others?"7 We might want to answer those questions from the context of our professional lives, particularly the last question. A profession is a culture, a way of seeing and acting in the world in which we live. A profession is learned from teachers, colleagues, and examples, both bad and good. We also learn from unstructured conversations and learn trust through the kindness and understanding of others who share our struggles.
Not valuing time with other physicians or allowing for informal conversations leads to a soulless efficiency and professional isolation that drains physicians of our ability to help ourselves, help each other, and help patients. Lunches with colleagues at a Chinese restaurant or grabbing coffee together in a safe place are investments that fewer and fewer physicians and systems in which they work are making. Physicians who have not had those experiences don't know what they are missing. Professional friendships and working relationships make human systems work better for humans. While solitude is a good and needed condition for reflection and rejuvenation, loneliness is the opposite. If we can't recreate doctors' dining rooms, we can at least create safe spaces and time for conversation and connections. Try calling a colleague and have a coffee or a meal together. Talk of many things and, perhaps, even talk about the work we do.

To read or post commentaries in response to this article, see it online at http://www.AnnFamMed.org/content/16/5/461.

Submitted February 22, 2018; submitted, revised April 16, 2018; accepted May 2, 2018.

Acknowledgment: For Ramon JC Murphy, MD, the storyteller.

\section{References}

1. Miller WL. Unfilled hunger: seeking relationships in primary care-a perspective from the keystone iv conference. J Am Board Fam Med. 2016;29(Suppl 1):S19-S23.

2. Carroll L. The walrus and the carpenter. In: Through the Looking Glass and What Alice Found There. 1872.

3. Mitchell J. Big Yellow Taxi. 1970 http://jonimitchell.com/music/song. $\mathrm{cfm}$ ? id $=13$.

4. Rogers E, Polonijo AN, Carpiano RM. Getting by with a little help from friends and colleagues: Testing how residents' social support networks affect loneliness and burnout. Can Fam Physician. 2016; 62(11):e677-e683.

5. Babenko O. Professional well-being of practicing physicians: the roles of autonomy, competence, and relatedness. Healthcare (Basel). 2018;6(1):E12.

6. Seppala E, King M. Burnout at work isn't just about exhaustion. It's also about loneliness. Harv Bus Rev. 6/29/2017, p2-4. https://hbr.org/ 2017/06/burnout-at-work-isnt-just-about-exhaustion-its-also-aboutloneliness.

7. Hughes ME, Waite LJ, Hawkley LC, Cacioppo JT. A short scale for measuring loneliness in large surveys: results from two populationbased studies. Res Aging. 2004;26(6):655-672. 